Carlos de Sousa $\mathrm{LUCCl}^{1}$ Valter FONTOLAN ${ }^{1}$ Thais Rose HAMILTON ${ }^{1}$ Renato KLU ${ }^{1}$ Vanessa WICKBOLD

Correspondência para: Professor Carlos de Sousa Lucci Rua Dr. Manoel Paiva Ramos, 60 apto SR-54-CEP 05351-015-S.Paulo, SP Email:cslucci@uol.com.br

Recebido para publicação: 03/06/2005 Aprovado para publicação: 24/10/2007

\title{
Processamento de grãos de milho para ruminantes: Digestibilidade aparente e "in situ"
}

\author{
1 - Curso de Medicina Veterinária da Universidade Santo Amaro, São Paulo - SP
}

\section{Resumo}

Seis carneiros machos Suffolk, com pesos de 35 a $40 \mathrm{~kg}$ e idades de 2 anos, dotados de cânulas de rúmen, foram utilizados para comparar dietas contendo milho em grãos processados para diferentes tamanhos de partículas: A) grosseiramente quebrado B) grosseiramente moído (quirera grossa) C) finamente moído (fubá). O delineamento empregado foi o "change-over", com dois grupos de três animais em período experimental de 84 dias. A ração era composta de farelo de soja $(14 \%)$, milho em grãos $(26 \%)$ e feno $(60 \%)$, medindo-se digestibilidade total e "in situ" do milho e do feno parâmetros ruminais: $\mathrm{pH}, \mathrm{N}-\mathrm{NH} 3$ e cinética de líquidos. Os resultados mostraram menores taxas de degradabilidade da matéria seca e proteína bruta do milho quando fornecido grosseiramente quebrado. Não ocorreram influências dos tratamentos sobre a fibra do feno ou sobre parâmetros ruminais. Concluiu-se que, no interior do rúmen, grãos de milho finamente moídos tiveram maior digestibilidade sem provocar alterações na digestão da fibra.

\section{Introdução}

Existem várias informações de como o milho em grãos deve ser fornecido para ruminantes. Assim, alguns autores sugerem moagem grosseira quando seu destino é mistura iniciadora para bezerros novos, enquanto finamente moído teria maior taxa de passagem pelo rúmen, podendo ser melhor digerido em intestinos de animais adultos. ${ }^{1,2}$

O milho, alimento importante pela sua riqueza em amido, é encontrado em proporções significativas nas misturas de alimentos concentrados destinadas a ruminantes, já que estes animais não aproveitam bem a gordura como fonte de energia. Contudo, são necessários cuidados para evitar-se fornecimento de quantidades excessivas de concentrados nas rações, pois isto diminui seus conteúdos em fibra, resultando em menor tempo de ruminação, menor secreção salivar e queda do pH do conteúdo do rúmen. 3,4,5 Todos esses fatores conduzem à redução da digestão da fibra no rúmen ${ }^{6,7}$, podendo ser lembradas modificações que resultam no aumento na taxa de passagem ${ }^{3}$, aumento do "lag time" da digestão da fibra ${ }^{6}$, e diminuição do número de bactérias celulolíticas ${ }^{8}$.

No Brasil a dieta dos ruminantes é preponderantemente composta de forragem volumosa surgindo como conseqüência queda acentuada na disponibilidade de alimentos durante o período de estiagem. Nesta situação, o fornecimento do milho em misturas concentradas garante a energia digestível suficiente para serem atingidos desempenhos melhores. Em estudo com ovinos recebendo rações com várias proporções de concentrados/volumosos ${ }^{9}$ foi obtida maior degradabilidade no rúmen com dieta contendo menos de $25 \%$ de concentrados. Com mais de $25 \%$ houve diminuição da degradabilidade dos volumosos, queda do $\mathrm{pH}$ ruminal e maiores concentrações de ácidos graxos voláteis, fato atribuído ao aumento do número de bactérias amiloliticas em relação as celulolíticas.

O tamanho das partículas dos alimentos influencia a taxa de saída do rúmen 
e altera a sua distribuição dentro do órgão: quanto menor a partícula maior a oportunidade de sua localização na parte dorsal onde a digestão microbiana é menos intensa. ${ }^{10}$ Já o fornecimento de grãos de milho inteiros (uma situação próxima dos grãos quebrados) implica em sua locomoção para saco ventral, tendo nesta situação uma permanência mais longa no interior do órgão. A redução no tamanho das partículas de forragens, por moagem ou peletização, talvez seja o principal fator na aceleração da taxa de passagem de sólidos pelo rúmen. ${ }^{11}$ A maior velocidade de passagem pode implicar em desvio do sítio de digestão, do rúmen para o intestino. ${ }^{5}$

Os objetivos do presente estudo foram avaliar as influências do grau de moagem no processamento de grãos de milho (quebrados, grosseiramente moídos ou finamente moídos) sobre fatores como digestibilidade, degradabilidade ruminal e parâmetros do metabolismo do rúmen.

\section{Material e Método}

Seis carneiros machos da raça Suffolk, todos castrados e de porte semelhante, portadores de cânulas ruminais, foram empregados para avaliar grãos de milho fornecidos em partículas de tamanhos diferentes, como componentes de mistura concentrada em rações contendo feno de capim "coast-cross" (Cynodon dactylon) como único volumoso. Foram determinadas taxas de digestibilidade e degradabilidade no rumen da matéria seca (MS) e proteína (PB) do milho e da MS e fibra em detergente neutro (FDN) do feno. Foram também medidos valores de $\mathrm{pH}$, concentrações de nitrogênio amoniacal (N-NH3) do conteúdo do rúmen e a cinética da fração líquida (volume, turn-over e taxas de passagem do líquido ruminal). Estas medidas serviram para comparar três tratamentos, correspondentes ao fornecimento de grãos de milho nas formas: A- quebrado, Bgrosseiramente moído (quirera grossa) e Cfinamente moído (fubá), dispostos em delineamento quadrado latino. ${ }^{12}$ Os seis ovinos foram separados em dois grupos de três animais, em um período experimental de 84 dias composto por três subperíodos de 28 dias. Comparações entre médias de tratamentos foram feitas aplicando-se o teste de Tukey, tendo como nível de significância $\mathrm{p}<0,05$.

As dietas dos três tratamentos foram balanceadas para conterem 15\% de PB, sendo constituídas por mistura concentrada (farelo de soja 35\%; milho em grãos 65\%) e feno como único volumoso. As quantidades fornecidas em todos os tratamentos foram iguais a $0,8 \mathrm{~kg}$ de mistura concentrada e 1,2 $\mathrm{kg}$ de feno, obedecendo à proporção 60: 40 como volumoso/concentrados, em base de matéria seca. As rações eram fornecidas em duas refeições, às $8 \mathrm{~h} 00$ e $15 \mathrm{~h} 00$.

Os períodos de coleta das amostras dentro dos subperíodos experimentais compreenderam dos dias 16 ao 20 para digestibilidade, de 21 ao 25 para provas de degradabilidade no rumen e de 26 a 28 para colheita de amostras do conteúdo ruminal visando à determinação de valores de $\mathrm{pH}$, de concentrações de nitrogênio amoniacal (N-NH3) e de cinética do liquido ruminal.

As provas de digestibilidade foram conduzidas pelo processo de coleta total de fezes, com emprego de bolsas coletoras arreadas aos animais. Teores de proteína bruta $(\mathrm{PB})$, fibra bruta (FB), extrato etéreo (EE), extrativo não nitrogenado (ENN), matéria seca (MS) e fibra em detergente neutro (FDN) foram determinados conforme procedimentos descritos ${ }^{13,14}$, estimando-se também valores de nutrientes digestíveis totais (NDT). As provas de degradabilidade in situ, potencial e efetiva (taxa de passagem $r=0,02$ ), empregaram técnica dos sacos de náilon ${ }^{15,16}$ realizando-se tempos de incubação de $0,1,2,4,6,12$ e 24 horas para MS e PB do grão de milho; e 0 , $6,12,24,48$ e 72 horas para MS e FDN do feno de Coast-Cross. Amostras de líquido ruminal foram coletadas para determinação de $\mathrm{pH}$, nos tempos de coleta $0,1,2,3,4$ e 5 horas após a primeira refeição do dia; para determinação das concentrações de nitrogênio amoniacal nos tempos 0,1 e 3 
horas após a primeira refeição do dia.

Polietilenoglicol peso molecular 4.000

(PEG), empregado como marcador de fase líquida, foi analisado em amostras de líquido ruminal colhidas nos tempos $0,1,2,3,4,5 \mathrm{e}$ 24 horas após a primeira refeição do dia, conforme Hyden ${ }^{17}$ com a finalidade de obterem-se valores de volume líquido ruminal, taxas de passagem de líquido pelo rumen em porcentagens por hora e número de revoluções do volume líquido no rúmen por 24 horas.

\section{Resultados e Discussão}

As médias dos valores de digestibilidade, em porcentagens (Tabela 1), acusam resultados significativamente diferentes apenas para o extrato etéreo, quando os tratamentos com milho quebrado $(67,54 \%)$ e quirera grossa $(67,34 \%)$ apresentaram maiores valores que o tratamento fubá (64,28\%). Tendo em vista o reduzido valor de gordura em rações de ruminantes e considerando-se ainda o pequeno conteúdo em gordura dos grãos de milho estes resultados perdem muito em importância prática.

Não foram encontradas diferenças entre tratamentos na digestibilidade da fibra das rações. Este fato permite deduzir que os diferentes tamanhos das partículas dos grãos de milho, provavelmente liberando amido mais ou menos prontamente para o meio ruminal, não influíram na capacidade de digestão da fibra da dieta, como haviam relatado alguns autores ${ }^{6,7,9}$ que trabalharam com diferentes proporções de amido na alimentação.

Resultados de degradabilidade ruminal dos grãos de milho e do feno (Tabela 2), tanto da matéria seca como da proteína bruta, indicaram valores significativamente menores para o tratamento com milho na forma quebrada, em relação aos demais. Entre os tratamentos com quirera grossa e fubá não ocorreram diferenças significativas. Tendo os grãos quebrados apresentado menor taxa de degradabilidade no interior do rúmen podese deduzir que processamentos de moagem mais fina implicaram em utilização mais rápida pelas bactérias ruminais, ou resultaram em velocidades de saída do rúmen mais altas. Thiago e Gill ${ }^{11}$ relataram taxas de saída do rúmen mais elevadas nos casos de grãos finamente moídos. No entanto foram obtidas digestibilidades semelhantes para os nutrientes do milho em quaisquer das formas administradas (exceção feita ao componente extrato etéreo) o que parece indicar um efeito compensatório de aproveitamento do amido entre bactérias do rúmen e enzimas intestinais. Discordando dos dados do presente estudo, existem relatos ${ }^{10}$ afirmando que alimentos em partículas menores resultam em menor fermentação ruminal devido à sua densidade implicar em localização diferente no interior do rúmen.

Tabela 1 - Médias de digestibilidade da proteína bruta, fibra bruta, extrato etéreo, extrativos não nitrogenados, matéria seca, FDN e dos teores de nutrientes digestíveis totais para as rações com milho quebrado, grosseiramente moído e fubá (valores em porcentagens)

\begin{tabular}{lcccc}
\hline \multicolumn{1}{c}{ ITEM } & $\begin{array}{c}\text { Tratamento A } \\
\text { Milho quebrado }\end{array}$ & $\begin{array}{c}\text { Tratamento B } \\
\text { Quirera grossa }\end{array}$ & $\begin{array}{c}\text { Tratamento C } \\
\text { Fubá }\end{array}$ & F \\
\hline Proteína bruta & 70,17 & 72,40 & 70,31 & NS \\
Fibra bruta & 53,90 & 54,27 & 53,23 & NS \\
Extrato etéreo & $67,54^{\mathrm{a}}$ & $67,34^{\mathrm{a}}$ & $64,28^{\mathrm{b}}$ & $\mathrm{P}<0,01$ \\
ENN & 65,00 & 64,54 & 65,96 & $\mathrm{NS}$ \\
Matéria seca & 62,21 & 62,61 & 62,77 & $\mathrm{NS}$ \\
FDN & 53,04 & 51,40 & 51,88 & $\mathrm{NS}$ \\
NDT & 61,59 & 61,85 & 61,84 & $\mathrm{NS}$
\end{tabular}

Letras diferentes na mesma linha significam diferença entre tratamentos 
Tabela 2 - Valores de degradabilidade potencial (dp) e degradabilidade efetiva (de) do milho (MS e PB) e do feno de coast cross (MS e FDN) nos diferentes tratamentos experimentais. Valores em porcentagens, sendo as taxas de passagem nos cálculos para degradabilidade efetiva $r=0,02$

\begin{tabular}{lcccc}
\hline \multicolumn{1}{c}{ ITEM } & $\begin{array}{c}\text { MILHO } \\
\text { QUEBRADO }\end{array}$ & $\begin{array}{c}\text { QUIRERA } \\
\text { GROSSA }\end{array}$ & FUBÁ & PROBABILIDADE \\
\hline de milho (MS) & $35,43^{\mathrm{a}}$ & $63,14^{\mathrm{b}}$ & $71,68^{\mathrm{b}}$ & 0,000 \\
de milho(PB) & $43,68^{\mathrm{a}}$ & $50,70^{\mathrm{b}}$ & $55,13^{\mathrm{b}}$ & 0,001 \\
dp milho(MS) & $46,59^{\mathrm{a}}$ & $76,48^{\mathrm{b}}$ & $84,00^{\mathrm{b}}$ & 0,000 \\
dp milho(PB) & $61,78^{\mathrm{a}}$ & $65,68^{\mathrm{b}}$ & $71,04^{\mathrm{b}}$ & 0,001 \\
de feno(MS) & 35,81 & 36,01 & 35,52 & 0,975 \\
de feno(FDN) & 31,61 & 31,14 & 30,82 & 0,933 \\
dp feno(MS) & 49,45 & 51,89 & 48,37 & 0,577 \\
dp feno(FDN) & 47,29 & 51,09 & 47,03 & 0,430
\end{tabular}

Letras diferentes na mesma linha indicam diferenças estatisticamente significativas $(\mathrm{p}<0,05)$

Os valores obtidos para $\mathrm{pH}$ de amostras de conteúdo ruminal, colhidas em diversos tempos após a primeira refeição do dia, não apresentaram diferenças estatisticamente significativas entre tratamentos (Tabela 3). Da mesma maneira, os valores referentes à cinética dos líquidos no rúmen, como taxa de passagem, volume (litros) e número de revoluções por 24 horas da fase liquida do conteúdo ruminal, bem como concentrações de nitrogênio amoniacal (N-NH3) do conteúdo do rúmen, não apresentaram diferenças consideradas estatisticamente significativas (Tabela 4).

A proporção volumoso/concentrados, mantida igual em todos os tratamentos, foi importante para manter valores de $\mathrm{pH}$ semelhantes, conforme já indicado em outras pesquisas $^{5}$, valores de $\mathrm{pH}$ desiguais

Tabela 3 - Médias de $\mathrm{pH}$ do líquido ruminal, nos diferentes tratamentos experimentais. Valores de probabilidade estatística (p)

\begin{tabular}{lcccccc}
\hline \multicolumn{1}{c}{ ITEM } & \multicolumn{5}{c}{ TEMPOS PÓS- ALIMENTAÇÃO (HORAS) } \\
\hline \multirow{2}{*}{ Milho Quebrado } & $\mathrm{Oh}$ & $1 \mathrm{~h}$ & $2 \mathrm{~h}$ & $3 \mathrm{~h}$ & $4 \mathrm{~h}$ & $5 \mathrm{~h}$ \\
\cline { 2 - 6 } Quirera Grossa & 6,13 & 6,33 & 6,34 & 6,407 & 6,26 & 6,11 \\
Fubá & 6,32 & 6,49 & 6,41 & 6,403 & 6,27 & 6,217 \\
P & 6,44 & 6,46 & 6,41 & 6,393 & 6,26 & 6,138 \\
& 0,483 & 0,770 & 0,892 & 0,993 & 0,992 & 0,791 \\
\hline
\end{tabular}

Tabela 4 - Médias de taxas de passagem (Tx pass) em porcentagens/hora; número de revoluções do líquido ruminal (Revol) por 24 horas; volume (Vol) em litros do líquido ruminal; concentrações de nitrogênio amoniacal (N-NH3) do líquido ruminal, nos diferentes tempos de coleta e tratamentos experimentais; valores de probabilidade estatística $(p)$

\begin{tabular}{lllllll}
\hline ITEM & Tx Pass & Revol & Vol & \multicolumn{3}{c}{ NH3 } \\
\hline & & & & $0 \mathrm{~h}$ & $1 \mathrm{~h}$ & $3 \mathrm{~h}$ \\
\hline Milho Quebrado & 4,493 & 1,077 & 10,15 & 20,95 & 18,65 & 26,53 \\
Quirerg Grossa & 6,772 & 1,627 & 13,26 & 22,21 & 20,83 & 25,91 \\
Fubá & 3,285 & 0,788 & 9,81 & 22,56 & 21,31 & 25,73 \\
P & 0,649 & 0,648 & 0,318 & 0,796 & 0,483 & 0,962 \\
\hline
\end{tabular}


provavelmente influiriam nas concentrações das bactérias celulolíticas presentes no conteúdo ruminal e alterações na digestibilidade da fibra. ${ }^{3,4}$ Desta forma, a menor degradabilidade dos grãos grosseiramente quebrados, registrada neste trabalho, mais provavelmente tenha ocorrido pela menor superfície de ataque oferecida às bactérias ruminais pelas partículas de milho de maior tamanho.

Os resultados de cinética dos líquidos do conteúdo ruminal demonstram semelhança entre tratamentos. A administração do milho em diferentes granulometrias na dieta dos ruminantes não alterou taxas de passagem do conteúdo líquido, volumes líquidos e número de revoluções por 24 horas do líquido ruminal. Se de fato a redução no tamanho das partículas de alimentos pode causar aumento na sua taxa de passagem ${ }^{11}$, nenhum efeito foi encontrado na fração líquida do conteúdo do rúmen, no presente trabalho.

\section{Conclusões}

Nas condições existentes nesta pesquisa é possível emitir as seguintes conclusões:

- Fornecendo-se a mesma quantidade de grãos de milho, a moagem dos mesmos resultou em aumento de sua digestibilidade no interior do rúmen, mas este fato foi compensado quando considerados todos os compartimentos do aparelho digestivo;

- No interior do rúmen, a digestibilidade elevada dos grãos de milho mais finamente moídos não influiu na digestibilidade do alimento volumoso.

\title{
Corn grain: Corn grain processing for ruminants: Apparent and "in situ" digestibility
}

\begin{abstract}
Six Suffolk rumen-canulated male lambs, with 35 to $40 \mathrm{~kg}$ live-weight and 2 years old, were used to evaluate diets containing corn grain processed in different particle sizes: A) roughly cracked B) roughly ground or C) finely ground. Statistical design was a change over with two groups of three animals in a total of 84 days of experimental period. Rations contained soybean meal (14\%), corn grain (26\%) and hay $(60 \%)$. Total and "in situ" digestibilities of corn and hay and ruminal parameters ( $\mathrm{pH}, \mathrm{N}-\mathrm{NH}-3$ and liquid cinetics) were measured. Results showed lower rumen digestion rates of corn dry matter and crude protein when fed roughly cracked. Treatments effects did not occur on hay fiber or ruminal parameters. It was concluded that finely crushed corn grain resulted in higher digestibility inside the rumen, without modification of fiber digestion.
\end{abstract}

\section{Referências}

1 LUCCl, C. S. Bovinos leiteiros jovens. S.Paulo: Nobel, 1969. $371 \mathrm{p}$

2 LUCCI, C. S. Nutrição e manejo de bovinos leiteiros. S.Paulo: Manole, 1977. 168p.

3 MCDONNEL, M. L.; KLOPFENSTEIN, T. J.; BRITTON, R. A. Associative effects: corn grain and cornstalks. J. Animal Science, v. 49, p. 267, 1979. Supplement 1.
Key words:

"In situ" digestibility. Corn.

Animal nutrition. Ruminants.
4 MOULD, F. L.; ORSKOV, E. R.; MANN, S. O. Associative effects of mixed feeds I. Effects of type and level of supplementation and the influence of the rumen fluid $\mathrm{pH}$ on cellulose in vivo and dry matter digestion of various roughages. Animal Feed Sci. Tech., v. 10, n. 1, p. 15-19, 1983.

5 SUDWEEKS, E. M.; ELY, L. O.; MERTENS, D. R. SISK, L. R. Assessing minimum amounts and form of roughages in ruminants diets: roughage value index system. J. Anim. Sci., v. 53, n. 5, p. 1406-1411, 1979. 6 MERTENS, D. R.; LOFTEN, J. R. The effect of start on 
forage fiber digestion kinetics in vitro. J. Dairy Sci., v. 63, n. 9, p. 1437-1441, 1980.

7 MILLER, B. G.; MUNTIFERERING, R. B. Effect of forage: concentrate on kinetics of forage fiber digestion in vivo. J. Dairy Sci., v. 68. n. 1, p. 40-44, 1985.

8 HENNING, P. A.; LINDEN, VAN DER; MATTEYSE, M. E.; NAUHAUS, W. R.; SCHWARTZ, H. M.; GILCHRIST, F. M. C. Factor affecting the intake and digestion of roughage by sheep fed maize stram supplemented with maize grain. J. Agric. Sci., v. 94 n. 3, p. 565-570, 1980.

9 MOSS, A. R.; GIVENS, I. D.; GARNSWORTHY, C. $P$. The effect of supplementing grass silage with barley on digestibility, in sacco degradability, rumen fermentation and methane production in sheep at two levels of intake. Animal Feed Sci. Tech., v. 55, p. 9-33, 1995.

10 THIAGO, L. R. L. Fatores afetando o consumo e utilização de forragens de baixa qualidade por ruminantes. In: Campo Grande: Empresa Brasileira de Pesquisa Agropecuária, 1984. 36 p.

11 THIAGO, L. R. L.; GILL, M. Consumo voluntário: teores relacionados com a degradação e passagem da forragem pelo rúmen. In: Campo Grande: Empresa Brasileira de Pesquisa Agropecuária, 1990. 65 p.

12 GOMES, F. P. Curso de estatística experimental. Piracicaba: ESALQ, 1985. 467p.

13 AOAC. Official methods of analysis. 1l ed. Washington D.C.: A.O.A C, 1980. 1051p.

14 GOERING, H. K.; VAN SOEST, P. J. Forage fiber analyses (Apparatus reagents, procedures and some applications). Washington D.C.: Agricultural Research Service, 1970. 19p. (Agriculture Handbook, 379)

15 MEHREZ, A. Z.; ORSKOV, E. R. A study of the artificial fiber bag technique for determination of the digestibility of feeds in the rumen. J. Agric. Sci., v. 88, p. 645-650, 1977.

16 ORSKOV, E. R.; HOVELL, D. D;. MOULD, F. Uso de la tecnica de la bolsa de nylon para la valuación de los alimentos. Prod. Animal Trop, v. 5, n. 3,. p. 213233, 1980 .

17 HYDEN, V. A turbidometric method for the determination of higher polyethylene glycols in biological materiais. D. Lantbr. Hogsk. Arbb., v. 22 , p. 139, 1956. 